Quebec Cooperative Study of

Friedreich's Ataxia

\title{
Effect of Alloxan Diabetes on Cerebellar Amino Acids
}

\author{
R. F. BUTTERWORTH, E. HAMEL, F. LANDREVILLE AND A. BARBEAU
}

SUMMARY: Rats rendered diabetic by alloxan monohydrate were studied to investigate the effect of increased blood glucose upon the concentration of various putative neurotransmitter amino acids in the cerebellum. No modification was found in the concentrations of glutamate, gamma aminobutyric acid $(G A B A)$, glutamine, glycine or taurine, but there was a significant decrease in the cerebellar concentration of aspartate in the diabetic animals. This raises the question of the specificity of the aspartic acid defect found in some form of ataxia.

RESUME: Nous avons étudié des rats rendus diabétiques par un traitement au monohydrate d'alloxan afin d'investiguer l'effet d'une augmentation de la glycémie sur la concentration de plusieurs acides aminés considérés comme neurotransmetteurs possibles dans le cervelet. Il n'y eut aucune modification dans les concentrations de glutamate, $G A B A$, glutamine, glycine ou taurine, mais la concentration cérébelleuse d'aspartate fut trouvée abaissée chez les animaux diabétiques. Ceci permet de mettre en doute la spécificité du déficit en acide aspartique trouvé dans les tissus de certains ataxiques.

From the Department of Neurobiology, Clinical Research Institute of Montreal.

Reprint requests for the complete supplement on Friedreich's ataxia (Phase 2, Part One) to: Dr. André Barbeau, Clinical Research Institute of Montreal, 110 Pine Avenue West, Montreal, Quebec, Canada, H2W 1 R7.

\section{INTRODUCTION}

There is a growing evidence that diabetes produces pathological changes in peripheral nerves and involvement of the nerve roots, spinal cord, brain stem and midbrain. For example, in an investigation (Olsson et al., 1968) of the peripheral and central nervous systems in nine patients with diabetes of 15-43 years duration, changes in the spinal cord were found in all. The predominant lesion of the spinal cord was degeneration of the long tracts and three patients showed degneration of the dorsal tracts, two of the ventral tracts and two of the spinocerebellar tracts.

The present study was undertaken to explore the effect of increased serum glucose induced by alloxan diabetes on the levels of six key amino acids in brain, specifically in cerebellum. Five of the amino acids, glutamic acid, GABA, aspartic acid, glycine and taurine have been shown to satisfy many of the criteria for candidate-neurotransmitters in the central nervous system.

\section{MATERIALS AND METHODS}

Twenty adult male SpragueDawley rats $(180-220 \mathrm{~g})$ were treated with alloxan monohydrate $(200 \mathrm{mg}$ per $\mathrm{kg}$ ) in $0.9 \%$ saline. Twelve rats received an equal volume of saline only. Presence of diabetes was confirmed by glycosuria (clinistix), hyperglycaemia (Dextrostix), marked polydipsia and a failure to gain weight. Twelve rats satisfying all four criteria were chosen for the study. Rats were sacrificed by decapitation, brains quickly removed and the cerebella dissected on ice. Tissues were stored in liquid nitrogen until the assay.
Cerebella were separately homogenized in 10 vol. perchloric acid $(0.48 \mathrm{M})$ and the amino acids GABA, glycine, glutamine, aspartic acid, glutamic acid and taurine assayed by the dansyl micro-assay technique as described by Joseph and Halliday (1975). Radiolabelled amino acids and ${ }^{3} \mathrm{H}$-dansyl chloride were purchased from New England Nuclear. Alloxan monohydrate was purchased from Calbiochem. Inc. All solvents used were reagent grade and double-distilled deionised water was used throughout the assay.

\section{RESULTS}

The levels of glutamic acid, aspartic acid, GABA, glutamine, glycine and taurine in cerebellum of rats made diabetic with alloxan $(200 \mathrm{mg}$ per $\mathrm{kg}$ ) are shown in Table 1. Only in the case of aspartic acid was there a significant difference between the alloxan-treated group and the saline-treated controls. In this case, the diabetic rats had a cerebellar aspartic acid level diminished $(p<$ 0.01 ) compared to controls, as analysed by student $t$ test.

\section{DISCUSSION}

When labelled glucose is metabolised by adult brain, a large portion of the carbon appears in amino acids and their derivatives, glutamic acid, GABA, glutamine and aspartic acid. This is due to active transamination reactions in which amino groups are exchanged between keto-acids from both the glycolytic pathway (for pyruvate) and the citric acid cycle (for $\alpha$-ketoglutarate and oxaloacetate) and various amino acids (see Figure 1).

A single intraperitoneal injection of alloxan (200 $\mathrm{mg}$ per $\mathrm{kg}$ ) into rats 


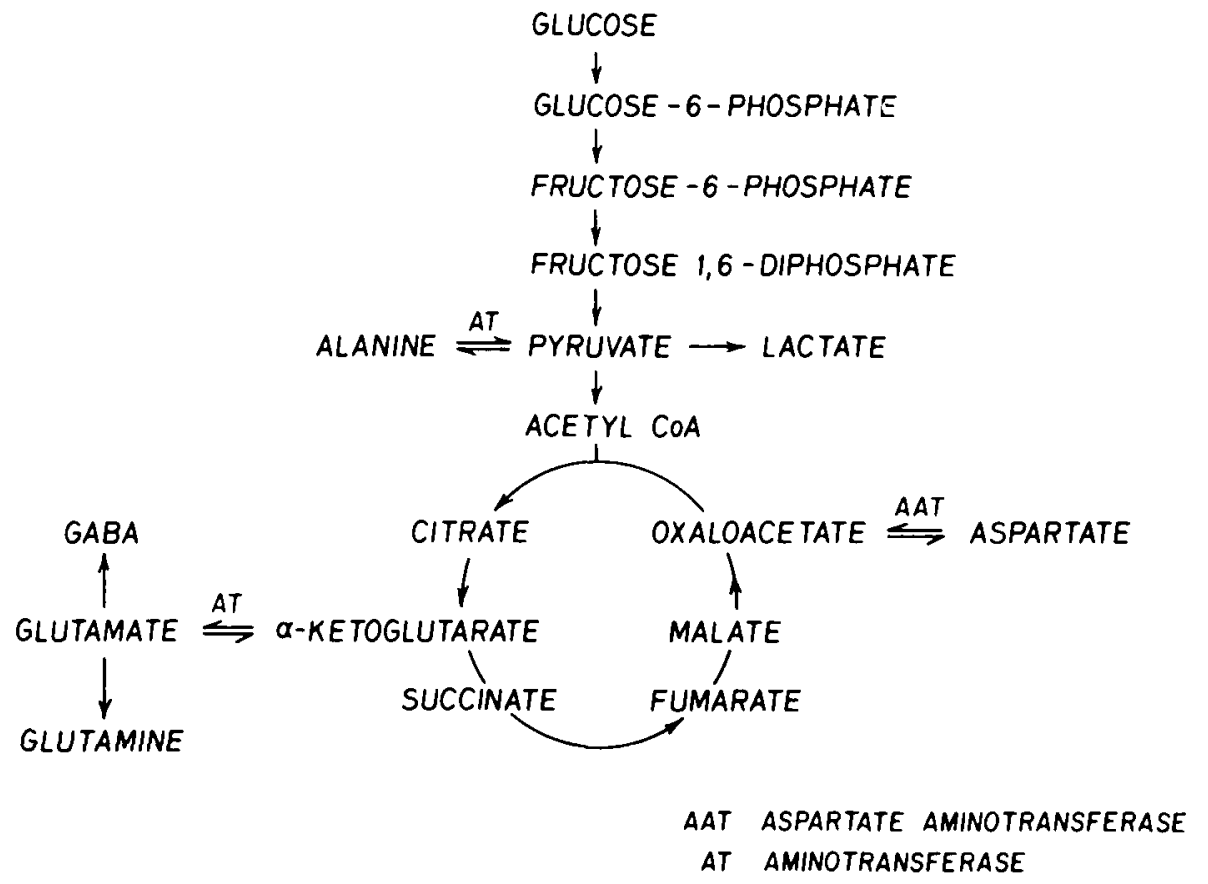

Figure 1: Metabolic pathways of labelled glucose in adult brain. has been shown to cause diabetes (Gomori and Goldner, 1943). The histological changes are necrosis and complete disappearance of the beta cells of the pancreatic islets. It has been shown that rat brain and spinal cord glucose levels are elevated 6-fold and 5-fold respectively in alloxan diabetes (Stewart et al., 1967). Cerebellar amino acid levels in alloxan diabetes were found by us to be unchanged in the case of GABA, glycine, glutamine, glutamic acid and taurine (Table 1). Aspartic acid, on the other hand was found to be significantly decreased in the cerebellum of alloxan diabetic rats ( $p<$ 0.01 as compared to control rats) as analysed by student $t$ test. This finding is interesting in view of the recent report (Jayashree and Nayeemunnisa, 1975) that aspartate aminotransferase activity was significantly increased in many brain areas (including cerebellum) of alloxan-diabetic rats. In addition, it has been demonstrated (BeloffChain et al, 1962) that incubation of cortex slices with radiolabelled pyruvate $(12 \mathrm{mM})$ produces within one hour a ratio of lactate: aspartic acid of 39:25 and that in the presence of glucose $(5 \mathrm{mM})$ the situation is modified and lactate: aspartate is produced in the ratio of $66: 12$. This terestingly, in insulin-induced hypoglycaemia, brain aspartic acid increases as hypoglycaemia develops and rapidly returns to normal during recovery, suggesting that aspartate may play an important role in the biochemical mechanism producing neurological abnormalities in hypoglycemic animals (Gorell, 1976).

It is tempting to speculate that there may be a relationship, based on these observations, between the finding of decreased aspartic acid in affected regions of spinal cord in Friedreich's ataxia (Robinson, 1968) and the well documented chronic glucose intolerance associated with the disease (Shapcott et al. 1976). Such a hypothesis then raises the question as to whether correction of the hyperglycaemia in Friedreich's ataxia may be of benefit in restoring the aspartic acid defect. Work continues in our laboratory to further elucidate this avenue of investigation.

\section{ACKNOWLEDGMENTS}

These studies were carried out under grants from la Fondation Jeanne-Mance (Hôtel-Dieu de Montréal), l'Association Canadienne de l'Ataxie de Friedreich and the Medical Research Council of Canada.

TABLE 1

EFFECT OF ALLOXAN DIABEIES ON AMINO ACIDS IN CEREBEILUMM
( $\mu$ mole per gm)
AMINO ACID CONCENTRATION
ALIOXAN DIABETES

$\mathrm{N}=12$

$10.16 \pm 0.42$

$\star 2.01 \pm 0.14$

$1.48 \pm 0.10$

$6.19 \pm 0.26$

$0.83 \pm 0.11$

$4.29 \pm 0.24$
CONTROL

$\mathrm{N}=11$
Glutamate

Aspartate

GABA

Glutamine

Glycine

Taurine
$10.16 \pm 0.31$

$2.67 \pm 0.15$

$1.30^{\circ} \pm 0.06$

$5.93 \pm 0.20$

$0.77 \pm 0.08$

$5.06 \pm 0.38$ 


\section{REFERENCES}

BELOFF-CHAIN, A., CATANZARO, R., CHAIN, E. B., LONGINOTTI, L., MASI. I. and POCCHIARI, F. (1962). The influence of glucose on acetate, alanine and pyruvate metabolism in rat cerebral cortical slices. Proc. Roy. Soc. B. 166, 168-171.

BRADFORD, H. F. (1968). Carbohydrate and energy metabolism, in: Applied Neurochemistry, A. N. Davison and J. Dobbing, Eds, Contemporary Neurology Series, F. A. Davis \& Co., (Philadelphia), pp: $222-250$.

GOMORI, G. and GOLDNER, M. G. (1943). Production of diabetes mellitus in rats with alloxan. Proc. Soc. Exp. Biol. Med. 54, 287-290.
GORELL, J. A., DOLKART, P. H. and FERRENDELLLI, J. A. (1976). Regional levels of glucose, anino acids, high energy phosphates and cyclic nucieotides in the central nervous system during hypoglycaemic stupor and behavioral recovery. J. Neurochem. 27, 1043-1049.

JAYASHREE, C. and NAYEEMUNNISA. (1975). Neurochemical correlates of alloxan diabetes: brain aminotransferase heterogeneity in the rat. Life Sci., 17 . 1159.1165 .

JOSEPH, M. H. and HALLIDAY, J. (1975). A dansylation microassay for some amino acids in brain. Anal. Biochem. 64, 389-402.

OLSSON, Y., SÄVE-SÖDERBERG, J., SOURANDER, P. and ANGERVALL, L. (1968). A pathoanatomical study of the central and peripheral nervous systems in diabetes of early onset and long duration. Path. Europ. 3, 62-79.

ROBINSON, N. (1968). Chemical changes in the spinal cord in Friedreich's ataxia and motor neurone disease. J. Neurol. Neurosurg. Psychiatr. 31. 330-333.

SHAPCOTT. D. MELANCON, S., BUTTERWORTH. R. F.. KHOURY. K.. COLLU. R.. BRETON, G., GEOFFROY. G., LEMIEUX, B. and BARBEAU, $A$. (1976). Glucose and insulin metabolism in Friedreich's ataxia. Can. J. Neurol. Sci. 3. 361-364.

STEWART. M. A.. SHERMAN. W. R.. KURIEN, M. M., MOONSAMMY, G. I. and WISGERHOF. M. (1967). Polyol accumulations in nervous tissue of rats with experimental diabetes and galactosaemia. J. Neurochem. 14, 1057-1066. 